\title{
APPLIED COMPUTATIONAL INTELLIGENCE FOR FINANCE AND ECONOMICS
}

\author{
Pedro Isasi, DAVID QuintanA, AND Yago SAEZ \\ Department of Computer Science, Universidad Carlos III de Madrid, Leganes, Madrid, Spain
}

ASUNCION MOCHON

Department of Applied Economics, UNED, Madrid, Spain

\begin{abstract}
This article introduces some relevant research works on computational intelligence applied to finance and economics. The objective is to offer an appropriate context and a starting point for those who are new to computational intelligence in finance and economics and to give an overview of the most recent works. A classification with five different main areas is presented. Those areas are related with different applications of the most modern computational intelligence techniques showing a new perspective for approaching finance and economics problems. Each research area is described with several works and applications. Finally, a review of the research works selected for this special issue is given.

Key words: computational intelligence, finance, economics, applications.
\end{abstract}

\section{INTRODUCTION}

The aim of this special issue is to present some relevant works on computational intelligence applied to finance and economics. The growing interest in joint research of these fields can be illustrated by the increasing amount of books and articles published in the recent years. The same trend can be observed in the growing number of conferences that hold special sessions devoted to these matters.

The number of feasible applications of computational intelligence in this area is huge and could cover anything from asset pricing or game analysis to time series forecasting. The range of instruments available includes traditional approaches from the computational intelligence field like fuzzy systems, neural networks, or evolutionary computation, to more recent ones like support vector machines, rough sets, or ant algorithms. All of them have already been used in economics and finance. In computational intelligence in economics and finance (Chen 2003) the authors compile most of the relevant works published until 2003. These works are a good reference regarding the different computational intelligence approaches applied in finance and economics until that time.

In the following section, an outline of the broad research lines in the field with pointers for relevant compilations and related research works will be given. The objective is to offer both context and starting points to those new to computational intelligence in finance and economics. Finally, the last section will be used to introduce the articles included in this special issue.

\section{COMPUTATIONAL INTELLIGENCE IN FINANCE AND ECONOMICS}

Often, economic systems consist of a number of individuals who are heterogeneous and whose rationality is usually bounded. Some of the most interesting research that are being currently carried out, has to do with agent-based simulation and the way we can use computational intelligence to deal with the rationality of economic agents. The analysis of these systems is based on assumptions regarding the behavior of these agents subject to a number of constraints. Therefore, the traditional approach to these problems requires important simplifying assumptions to make the search of an analytical solution feasible. 
Nevertheless, the increasing computing resources available has opened up for researchers new opportunities in the field. Among these, agent-based simulation is gaining a lot of momentum. A specific branch, agent-based computational economics (ACE) is establishing a strong research field on its own. This methodology models markets from the bottom up through the interaction of a number of agents. The aim of the ACE is not only observing the behavior of these agents, but also the emergent properties arising from their interaction. The importance of this emergent behavior must be emphasized. The dynamics of this interaction reveals the effect of combining a set of agents, and its complexity makes the aggregate behavior difficult to predict. Given that, this challenge is usually beyond the limits of mathematical analysis, simulation plays a key role in tackling this kind of problem. Those new to the field willing to gain some insight into this area might consider several research works, such as LeBaron (2000), Tesfatsion (2002), and Tesfatsion and Kenneth (2006).

Once the decision to perform agent-based simulation has been made, the issue of modeling the individual's behavior and interaction with other agents is raised. The fact that the conduct of these agents is usually heterogeneous and adaptive, allows for the study of boundedly rational agent learning and decision making. This rationality might be implemented in different ways. As is suggested in Sargent (1993), agents might be sure of their model but unsure of the parameters values; unsure of both their models and parameters; or even unsure about which of the two previous alternatives should be followed. This behavior might be achieved by means of computational intelligence.

Among the wide range of alternative approaches to provide the agents with learning capabilities, the most represented among the ones present in this special issue fall within the field of evolutionary computation. This field is usually divided into four main areas: evolutionary programming (Fogel 1962; Owens, Fogel, and Walsh 1996) evolutionary strategies (Rechenberg 1965; Schwefel 1965), genetic algorithms (Holland 1962, 1975), and genetic programming (Koza 1992). Each of these areas has been successfully used to tackle problems in the fields of economics and finance. Anyone interested in this topic would find it useful to review the book edited by Chen (2002), and more specifically the last chapter of "Evolutionary computation in economics and finance: A bibliography," Chen and Kuo (2002). These works classify more than 380 publications produced from 1986 to early 2001 and identify five main application domains:

- Financial economics;

- Games and industrial organization;

- Macroeconomics;

- Econometrics;

- Preference, risk, and uncertainty.

Apart from these application areas the authors identify additional fields where evolutionary computation may be applied, such as: labor economics, transportation and regional economics, and experimental economics. This classification suggested for evolutionary computation, could well be extended to computational intelligence as a whole.

\subsection{Financial Economics}

Financial economics is likely to be the most active research application domain among the five mentioned. The use of computational methods in this area is widespread, which is not surprising. The combination of increasing processing power and the unprecedented amount of financial data available has extended the range of opportunities for exploring the field. Researchers currently have access to computational resources that are letting them 
obtain: process and analyse high financial frequency data (Bolland and Connor 1997), price complex financial products (Malliaris and Salchenberger 1993), or analyze market behavior (Holland et al. 1994; Lettau 1997). With these methods, the need for simplifying assumptions is less and the role of data as driver is strengthened. In addition, the amount of money that flows into the global financial market makes the reward of extracting exploitable regularities from financial data very attractive. As a result, more efforts are needed to gain an edge through computational intelligence. The literature in this field can be divided into two broad categories: agent-based computational finance and financial engineering.

The first one covers mainly market simulation where agents adapt their behavior according to the circumstances or even if the market rules evolve with time.

The second includes issues like financial forecasting, trading strategy generation, portfolio management, asset pricing, etc. Chen (2003), Trippi and Turban (1992), and Refenes (1994) collect a good number of examples. Anyone interested in a more detailed explanation on the scope and agenda of computational finance research could find Tsang and MartinezJaramillo (2004) useful.

\subsection{Games and Industrial Organization}

The games and industrial organization category is again a very active research area. The use of computational intelligence helps to overcome the simplifying assumptions, most notably, the perfect rationality imposed by alternative approaches. Among the problems considered in this branch, it could be mentioned bargaining and auctions (Andreoni and Miller 1995; Saroop and Bagchi 2002), repeated prisoner's dilemma (Fogel 1993), or others like the repeated ultimatum game (Feltovich and Duffy 1999) and the duopoly and oligopoly games (Chen and Ni 2000). References regarding cooperation, coalition and coordination are also frequent and usually driven by evolutionary computation (Vriend 1995).

\subsection{Macroeconomics}

Macroeconomics is another broad area of interest. Arifovic surveys applications of evolutionary algorithms in macroeconomic models (Arifovic 2000). The problems in this domain include the study of models such as the cobweb (Arifovic 1994) or overlapping generation (Bullard and Duffy 1998). A specific example could be the classic study that replicated the emergence of money from a barter economy (McGrattan, Marimon, and Sargent 1990). In this context, computational intelligence has been used to simulate complex adaptive phenomena, such as an optimization technique or to analyze data. Additional relevant examples worth mentioning would be contributions to research on economic growth (Silverberg and Verspagen 1999) or economic transition (Chen and Yeh 2000).

\subsection{Econometrics}

Computational intelligence has also been extensively applied in econometrics to both parametric and nonparametric models. The applications include parameter estimation (Dorsey and Mayer 1995), hypothesis testing (Chen and Yeh 1996) or model discovery (Fischer and Leung 1998).

In this area, neural networks, evolutionary computation and hybrid solutions like evolutionary neural networks account for a good portion of the literature. 


\subsection{Preference, Risk, and Uncertainty}

The preference, risk, and uncertainty domain includes articles mostly devoted to studying the preference formation process. In this context, computational intelligence provides the flexibility required to model and test endogenous preference formation processes. The enhancement frees the researcher from the traditional assumption of risk aversion (Sargent 1993) and allows for the exploration of alternatives to exogenously given preferences. This has resulted in new ways to explain observed phenomena such as, for instance, the fact that both risk aversion and embrace might be explained through the length of the evaluation cycle (Szpiro 1997; Cacho and Simmons 2000).

Regarding the specific contents of this special issue, most of the articles fall within the ACE framework. Among the mentioned application areas, the most represented are the first and the second ones, that is, financial economics and games and industrial organization.

\section{SPECIAL ISSUE CONTENTS}

This special issue is a compilation of relevant recent works, made by the research groups currently working in this area. It includes three articles on games and industrial organization. Two of them are focused on auctions and the other one analyzes oligopoly games. The first one, "Learning Oligopolistic Competition in Electricity Auctions," contributed by Guerci et al., addresses the problem of auction markets efficiency within the context of electricity markets. The authors analyze the relative efficiency of the main two auction mechanisms used in this context in the framework of the learning games approach. The second one, "Effects of a Rationing Rule on the Ausubel Auction: A Genetic Algorithm Implementation" offers a different approach. The authors stress the importance on the learning process of specific agents and present a genetic algorithm that derives bidding strategies for the Ausubel auction with private values and dropout information considering several rationing rules. Alkemade et al. present a methodological piece of research that is focused on the ways to improve the use of evolutionary computation within the ACE framework. In this case the authors aim to show, through the Cournot oligopoly game, that the evolutionary computation parameters must be set correctly to avoid problems with the results.

This issue also presents two research works on financial market simulation. The first one, titled "Price Dynamics, Informational Efficiency, and Wealth Distribution in Continuous Double-Auction Markets," deals with the properties of the continuous double-auction trading mechanism using an artificial market populated by heterogeneous computational agents. The authors analyze how changes in the population of traders and in the market microstructure characteristics affect price dynamics, information dissemination and distribution of wealth across agents. The starting point for the second one is the observation that most agentbased simulation models of financial markets are discrete-time in nature. Boer, Kaymak, and Spiering's contribution to this special issue is a piece or research that looks into the degree to which these models are extendible to continuous-time, asynchronous modeling of financial markets.

The remaining two articles could both be considered in the mentioned second broad category of the financial economics domain or in the econometrics one. The first of the mentioned research works presents a biological brain inspired learning system based on human pattern recognition and a gene selection process called genetic complementary learning (GCL) to predict the behavior of financial time series and bank failure. The suggested solution is an evolving and autonomous system that frees the users from the process of manual rule construction or modeling. Finally, Cheng, Quek, and Mah present a financial event prediction method based on an adaptive neural fuzzy inference system (ANFIS) model. The system 
provides predictions for the moment in which the market takes an anticipatory position before an event occurs, the movement in the indices, and the variation in the volume traded.

\section{CONCLUDING REMARKS}

An introduction to applied computational intelligence in finance and economics has been presented in this article. To obtain a better understanding of the different fields where the computational intelligence techniques can be used within the economics and financial problems, a classification is proposed following Chen and Kuo (2002). There are five main areas with relevant works, which can serve as an adequate starting point. These areas are summarized as follows: financial economics. games and industrial organization, macroeconomics, econometrics and preference, risk and uncertainty. The articles included in this issue make significant contributions to the literature of computational intelligence among these areas. Our hope is to share this opinion with the readers and, and hopefully to stimulate them to enlarge the base of knowledge of this eminently interdisciplinary area.

\section{ACKNOWLEDGMENTS}

We would like to thank all the evaluation committee staff for their help in the reviewing process, and the Spanish-funded research MCyT project OPLINK, reference TIN200508818-C04-02, for their support.

\section{REFERENCES}

ANDREONI, J., and J. H. MiLler. 1995. Auctions with artificial adaptive agents. Games and Economic Behavior, 10(1):39-64. Available at http://ideas.repec.org/a/eee/gamebe/v10y1995i1p39-64.html.

ARIFOVIC, J. 1994. Genetic algorithm learning and the cobweb model. Journal of Economic Dynamics and Control, 18(1):3-28. Available at http://ideas.repec.org/a/eee/dyncon/v18y1994i1p3-28.html.

ARIFOVIC, J. 2000. Evolutionary algorithms in macroeconomic models. Macroeconomic Dynamics, 4(3):373414. Available at http://ideas.repec.org/a/cup/macdyn/v4y2000i3p373-414.html.

BolLAND, P. J., and J. T. CONNOR. 1997. A constrained neural network kalman filter for price estimation in high frequency financial data. International Journal of Neural Systems, 8(4):399-415.

BULLARD, J., and J. DUFFY. 1998. A model of learning and emulation with artificial adaptive agents. Journal of Economic Dynamics and Control, 22(2):179-207.

CACHO, O., and P. Simmons. 2000. A genetic algorithm approach to farm investment. Australian Journal of Agricultural and Resource Economics, 43(3):305-322.

CHEN, S. C. 2003. Computational Intelligence in Economics and Finance. Springer-Verlag, New York.

CHEN, S. H. 2002. Evolutionary Computation in Economics and Finance. Springer-Verlag, New York.

CHEN, S. H., and T. KUO. 2002. Evolutionary computation in economics and finance: A bibliography. In Evolutionary Computation in Economics and Finance. Edited by S. Chen. Springer-Verlag, New York, pp. 419455.

CHEN, S. H., and C. C. NI. 2000. Simulating the ecology of oligopolistic competition with genetic algorithms. Knowledge Information Systems, 2(3):285-309.

CHEN, S. H., and C. H. YEH. 1996. Bridging the gap between nonlinearity tests and the efficient market hypothesis by genetic programming. In Proceedings of the IEEE/IAFE 1996 Conference on Computational Intelligence for Financial Engineering. Crowne Plaza Manhattan, New York, NY, IEEE Press, pp. 34-39. 
Chen, S. H., and C. H. YeH. 2000. Simulating economic transition processes by genetic programming. Annals of Operations Research, 97:265-286.

DORSEY, R. E., and W. J. MAYER. 1995. Genetic algorithms for estimation problems with multiple optima, nondifferentiability, and other irregular features. Journal of Business \& Economic Statistics, 13(1):53-66.

Feltovich, N., and J. DUFFy. 1999. Does observation of others affect learning in strategic environments? An experimental study. International Journal of Game Theory, 28(1):131-152.

FISCHER, M. M., and Y. LEUNG. 1998. A genetic-algorithms based evolutionary computational neural network for modelling spatial interaction data. The Annals of Regional Science, 32(3):437-458.

FOGEL, D. B. 1993. Evolving behaviors in the iterated prisoner's dilemma. Evolutionary Computation, 1(1):77-97.

FoGEL, L. J. 1962. Autonomous automata. Industrial Research, 4:14-19.

HolLAND, J. H. 1962. Outline for a logical theory of adaptive systems. Journal of the ACM, 9(3):297-314.

Holland, J. H. 1975. Adaptation in Natural and Artificial Systems. The University of Michigan Press, Ann Arbor, MI.

Holland, J. H., B. LeBaron, R. G. Palmer, W. B. Arthur, and P. Tayler. 1994. Artificial economic life: A simple model of a stockmarket. Physica D, 75(1-3):264-274.

KozA, J. R. 1992. Genetic Programming: On the Programming of Computers by Means of Natural Selection. MIT Press, Cambridge, MA.

LEBARON, B. 2000. Agent-based computational finance: Suggested readings and early research. Journal of Economic Dynamics and Control, 24( 5-7): 679-702.

LETTAU, M. 1997. Explaining the facts with adaptive agents: The case of mutual fund flows. Journal of Economic Dynamics and Control, 21(7):1117-1147.

MALLIARIS, M., and L. SALCHENBERGER. 1993. A neural network model for estimating option prices. Applied Intelligence, 3:193-206.

McGrattan, E., R. MARimon, and T. J. SARGent. 1990. Money as a medium of exchange in an economy with artificially intelligent agents. Journal of Economic Dynamics and Control, 14(2):329-373.

Owens, A. J., L. J. Fogel, and M. J. WALSH. 1966. Artificial Intelligence Through Simulated Evolution. John Wiley, New York.

RECHENBERG, I. 1965. Cybernetic solution path of an experimental problem. Technical Report 1122, Royal Aircraft Establishment, Farnborough Library Translation.

Refenes, A. P. 1994. Neural Networks in the Capital Markets. John Wiley, New York.

SARgent, T. J. 1993. Bounded Rationality in Macroeconomics. Clarendon Press, Oxford.

SAROOP, A., and A. BAGCHI. 2002. Artificial neural networks for predicting final prices in ebay auctions. In 12th Workshop on Information Technology and Systems (WITS 2002), pp. 19-24.

Schwefel, H. P. 1965. Kybernetische Evolution als Strategie der Experimentellen Forschung in der Strömungstechnik. Master's Thesis, Technical University of Berlin.

SilverberG, G., and B. Verspagen. 1999. Evolutionary theorizing on economic growth. In The Evolutionary Principles of Economics. Edited by K. Dopfer. Cambridge University Press, Norwell, MA.

SZPIRO, G. G. 1997. The emergence of risk aversion. Complexity, 2(4):31-39.

TESFATSION, L. 2002. Agent-based computational economics: Growing economies from the bottom up. Artificial Life, 8(1):55-82.

TESFATSION, L., and L. J. KENNETH. (Editors). 2006. Handbook of Computational Economics, Vol. 2 of Handbook of Computational Economics. Elsevier, Amsterdam, The Netherlands.

TRIPPI, R., and E. TURBAN. (Editors). 1992. Neural Networks in Finance and Investing: Using Artificial Intelligence to Improve Real World Performance. McGraw-Hill, New York.

TSANG, E., and S. MARTINEZ-JARAmiLlo. 2004. Computational finance. IEEE Connections, 2(3):8-13.

VRIEND, N. J. 1995. Self-organization of markets: An example of a computational approach. Computational Economics, 8(3):205-231. 